hormone promotes synthesis of ribonucleic acid (R.N.A.) and protein, ${ }^{11}$ sleep may have an important role in growth, in the healing of injured tissues, and in the restoration of our bodies after exercise. Most of us have ceased to grow in height but depend on synthetic processes for renewal of tissues-for example, the normal growth of new cells for the skin.

The other main type of normal sleep, known as the paradoxical phase, usually occupies a quarter of the night. I. Haider and I. Oswald ${ }^{12}$ reported that in the weeks after severe poisoning with hypnotic drugs it was the paradoxical phase of sleep which had higher priority than the slow-wave phase of orthodox sleep, and this was at a time when brain repair after chemical injury might be inferred. The large cerebral blood flow during the paradoxical phase of sleep, ${ }^{13}$ the latter's association with the time of life when brain growth is rapid, ${ }^{14}$ its proportionally reduced appearance in mental defect ${ }^{15}$ and in senility, ${ }^{16}$ when synthetic processes in the brain are impaired, have been seen as indicating that paradoxical sleep may be linked with synthetic and restorative functions in the brain, while orthodox sleep may serve as a restorative period for most other body tissues. ${ }^{17}$

The importance of sound sleep for healing and for recovery from illness has long been inferred, but recent advances begin to illuminate unsuspected mechanisms. Since hypnotic drugs and noisy hospitals both impair the natural features of sleep, either might indirectly interfere with the synthetic processes necessary for healing of tissues. A patient who is subject to the presence of noise, discomfort, and natural fears will find a hypnotic of great comfort, but the routine prescription of such drugs merits renewed and critical scrutiny.

\section{Whither General Practice?}

In the last 20 years general practice has been the subject of countless articles and at least ten major investigations. This month two more have been published: the B.M.A. Planning Unit's report ${ }^{1}$ on primary medical care and the second report ${ }^{2}$ on the present state and future needs of general practice from the Royal College of General Practitioners.

The Planning Unit working party ${ }^{3}$ set out to find the best form of primary care-the first contact made by someone who wants medical advice or treatment. Solutions it considered included polyclinics, feldshers, and self-referral to hospital; but for Britain anyway there seemed no serious rival to the general practitioner. The report comments, however, that "the prefix 'general' is now inappropriate because it tends to be contrasted misleadingly with the word 'specialist' and so inhibits clear thinking about the future development of this branch of medicine ... The doctor practising in the specialty will not be a generalist."

The report gives a gloomy picture of the current state of general practice, with family doctors believing themselves undervalued, fewer entrants to this branch of medicine, and the "perpetuation of low standards of work in too many practices." The remedy it suggests is to narrow the range of the interests of the primary physician and so give him the chance to deal in greater depth with what he retains. This change in the quality and content of his work, says the report, should make the job more satisfying and so more attractive. Given this conclusion, the suggestions made in the report are logical. It sees no future for the general practitioner-obstetrician-though the primary physician will clearly need to retain an interest in ante- and post-natal care. Patients with diseases of the skin, eyes, ear, nose, and throat could be seen initially at a hospital clinic, bypassing the primary physician. Alternatively, when primary physicians are practising as a group, each doctor could take responsibility for all the primary care in one specialty. At the same time better organization of his practice, including more use of para-medical workers, would further lighten the doctor's work.

Freed of much routine and part of the clinical content of his work, the primary physician would be able to expand his interests elsewhere. "For the doctor who is able to use sociological and psychological frames of reference," says the report, "much work which previously seemed unintelligible or trivial, and often irremediable and frustrating, can become intelligible, more manageable and more rewarding." It sees sociology and psychology as of similar importance in primary care to clinical and social medicine.

The clinical skills of the primary physician, says the report, should enable him "not so much to attach a diagnostic label as to unravel the undifferentiated clinical problem which is often a complex of physical, emotional, and social factors, and to take or initiate appropriate action." Training in the behavioural sciences and full support from the community social services are seen as necessary for the proper use of these skills. But the shedding of part of the general practitioner's blanket responsibility for primary care would, however, mean changes in his contract and also in the pattern of clinical work referred to hospital. Initially at least there would be strong opposition from the hospitals to the new burden of sub-consultant work, while many doctors firmly believe that total primary care is the essential feature of general practice.

The study from the Royal College sets out a picture of general practice as it now is. Since the introduction of the N.H.S. major changes have occurred by a process of evolution. Doctors work in larger groups; and many more now use appointment systems. There has been little change in the last ten years in the number of patients seen each day, but fewer home visits are made. Of the conditions seen in general practice disorders of the respiratory tract, skin, and digestive tract between them still account for $50 \%$ of consultations; emotional disorders $(12 \%)$ and preventive measures $(10 \%)$ together account for less than a quarter.

Another trend in general practice has been the wider use of practice nurses, social workers, and ancillary staff of all kinds. Purpose built premises have also increased efficiency: so it is not, perhaps, so surprising that the College report should conclude that general practitioners have more time. Partly this may be because "paradoxically, the growth of knowledge has made the practice of medicine simpler." The College report leaves open the best use of this slack-maybe in teaching, in research, or in preventive medicine; just possibly in looking after much larger numbers of patients. It comments that in Scandinavia as many as 8,000 patients can be cared for by one doctor (with a group practice and adequate ancillary help). Clearly such a form of primary care would be in complete contrast to the sociologically orientated primary physician

1 British Medical Association Planning Unit, Primary Medical Care, London, B.M.A., 1970.

2 Royal College of General Practitioners, Reports from General Practice XIII, Present state and future needs of general practice, 2nd ed., London, R.C.G.P., 1970.

3 The members of the working party were: Professor Margot Jefferys, chairman; Dr. Donald Irvine, Dr. Thomas Arie, Dr. A. H. Duncan, Dr. G. H. Curtis Jenkins, Dr. R. L. Lindon, Professor R. F. L. Logan, Dr. G. N. Marsh, Dr. P. C. Reynell, and Dr. (now Professor) I. R. McWhinney.

- Health Centres and Group Practices. London, B.M.A., 1966.

5 The New General Practice. London, B.M.A., 1968. 
described by the Planning Unit's report: it would concentrate on the early diagnosis of organic disease, leaving primarily social problems to the community social services.

The two reports are agreed that general practitioners (or primary physicians) must be given the right to admit their patient to beds in local, cottage hospitals and there retain clinical control of them. Both see lack of this facility as a major disincentive to recruitment. They also agree on the need for better vocational training and the better organization of medical services, with more use of health centres and larger groups.

What neither study has shown, however, is that changes of this kind will necessarily attract young doctors into practice. Recruitment is still very slow. Last year 1,085 doctors left general practice, and 1,257 entered it, of whom 167 were born outside Britain. The total number of general practitioners is still below that ten years ago, despite a rise in the population. But it does not follow that radical solutions must be devised. General practitioners have always refused to contemplate any interference with their independent contractor status or with their right to organize their practices as they wish. In the last lecade there has been a gradual evolution in practice methods and organization, but there has been little evidence that family doctors want to give up any part of the primary care of their patients. Indeed many believe that with modern organization they could cope with more patients with no lowering of standards-though the growth of monopoly practices may have adverse effects on the doctor-patient relationship.

The pattern and content of general practice will change, and these two new reports will stimulate thought and discussion on the direction it will take. The need for flexibility in approaching reform was recognized by the working party, which called for "varied experiments in delivering primary medical care, capable of evaluation ..." But the process of change will continue to be publication by innovators of their ideas through the College and the journals, and eventual acceptance of some of these new methods by others-but in their own time. Series in the B.M. F. on health centres and group practices" and on "the new general practice" 5 have shown how wide the interest is in this field. In the end, however, general practice will continue to attract recruits from doctors who wish to be independent, to organize their own day, their way of life, and their work. Some will want to concentrate on social medicine; others on psychotherapy, and yet others on, say, manipulative medicine. Any attempt by authority to dictate changes will be resented, and quite rightly.

\section{Unhealthy Tan}

The belief that a sun-tanned skin denotes health gives consolation to many a holiday-maker as well as profit to hotel keepers. Yet ironically the candidate for the M.R.C.P. has to learn some thirty causes for pigmentation of the skin of which nearly all are pathological except pregnancy.

Misunderstanding may have arisen from the notion that the tanned outdoor worker, such as the farmer, is leading a healthier life than the pale office clerk. The fact is that the noxious effects of solarization of the white skin far outweigh the beneficial. Certainly sunlight forms vitamin D in the skin, but a normal diet meets ordinary requirements, and people who need supplements can take them by mouth. Actinotherapy and heliotherapy have lost their former role in the management of tuberculosis; they remain of some value in the treatment of a few skin diseases and are important, but only in a supporting role, in the treatment of acne vulgaris and psoriasis. Dermatologists nowadays see sunlight and, in particular, ultra-violet radiation, as mostly detrimental-as the exciting factor in the photodermatoses and causing photosensitivity reactions in people with certain genetic and metabolic diseases. Admittedly in Great Britain sunlight is not often strong, but in other countries it is of serious concern. A recent review by A. M. Kligman ${ }^{1}$ on the destructive effect of sunlight on human skin is to be especially noted in this context.

The effects of strong sunlight on normal white skin may he divided into acute and chronic. The former include erythema (which may progress to bullae), pigmentation, and epidermal thickening. Most of these effects are due to the shortest, ultra-violet, wavelengths. Sunburn erythema indicates damage to the skin; there is no convincing reason to believe that this inflammatory reaction has any beneficial quality. The pigmentary response and epidermal thickening are defensive reactions.

Pigmentation from sunlight is of two types. Firstly, there may be evanescent "pigment darkening" due to rapid photooxidation cf partly bleached preformed melanin. The more important delayed type of pigmentation, melanogenesis, is due to the enzymatic formation from tyrosine, triggered by ultra-violet radiation, of new melanin in the melanocytes of the basal layer of the epidermis. In races with brown and black skins this melanin is being constantly produced owing to genetic factors, so that the Negro's skin, for example, is better adapted than the European's to withstand the destructive effects of strong sunlight. This is particularly true of exposure over long periods.

Long-term exposure of white skin to strong sunlight produces "ageing" changes, which can culminate in epithelioma. The earlier changes such as atrophy, telangiectasis, and keratoses may be seen in young people in Australia, and similar changes have been noted in Texas and elsewhere. But genetic factors are also important, as shown by the prevalence in Ireland of squamous cell epithelioma of the exposed skin, where the rates are greater than expected from the hours of sunshine.

Xeroderma pigmentosum, in which "ageing" of the skin from ultra-violet radiation is greatly accelerated, is a rare genetic condition due to a recessively inherited autosomal gene. The skin lesions are evidently due to a failure of repair processes after damage to D.N.A. provoked by ultra-violet radiation. ${ }^{23}$ Recent work ${ }^{4}$ has shown how even short exposure of normal human skin to ultra-violet radiation leaves easily detectable damage of D.N.A. But normally such lesions seem to be looked after by the healthy processes of repair.

Normal persons acquiring their sunburn in small doses find after three days or so that the delayed pigmentary changes and epidermal thickening allow longer doses of ultra-violet radiation to be tolerated. Barrier preparations may help in the preliminary stages, but it is almost impossible to obtain tanning from sunlight without some burning. In fact the two together probably produce the aesthetically desired "bronze colour" that fashion dictates. Pure pigmentary reactions, which can be produced experimentally in white skin,

\footnotetext{
Kligman, A. M., Fournal of the American Medical Association, 1969, 210,

2377.
Cleaver, J. E., Nature, 1968, 218, 652.

3 Cleaver, J. E., fournal of Investigative Dermatology, 1970, 54, 181.

4 Tan, E. M., and Stoughton, R. B., fournal of Investigative Dermatology, $1969, \mathbf{5 2}, 537$.

Pathak, M. A., Fitzpatrick, T. B., and Frenk, E., New England Fournal of Medicine, 1969, 280, 1459.
} 